\title{
Torzonomy ornd Systemantic Two new species of Omyomymar Schauff (Hymenoptera: Mymaridae) from the Indian Himalayan Region with a key to Indian species
}

Registered on ZooBank: urn:Isid:zoobank.org:pub:95545052-A416-4238-A778-64C94305F49F

\author{
Prince Tarique Anwar ${ }^{\circledR \oplus}$, Shahid Bin Zeya ${ }^{1 \oplus}$ \& Syeda Uzma Usman ${ }^{2}$
}

1. Department of Zoology, Aligarh Muslim University, Aligarh, Uttar Pradesh, India. 2. Department of Zoology, Mohammad Ali Jauhar University, Rampur, Uttar Pradesh, India.

\section{EntomoBrasilis 14: e960 (2021)}

\section{Edited by:}

Alberto Moreira Silva-Neto

Article History:

Received: 01.viii.2021

Accepted: $15 . i x .2021$

Published: 27.ix.2021

Corresponding author:

Prince Tarique Anwar

७ ta.friday@gmail.com

Funding agencies:

$\checkmark$ Without funding declared
Abstract. Two new species of the genus Omyomymar Schauff (Hymenoptera: Mymaridae), Omyomymar sudhiri sp. nov. Anwar \& Zeya and Omyomymar supremus sp. nov. Anwar \& Zeya are described from the Indian Himalayan regions. An identification key to Indian species is provided. All the previously recorded and described species of the genus are analyzed and discussed.

Keywords: Chalcidoidea; description; fairyfly; India; record; taxonomy. $\mathrm{n}$ his study ScHAUfF (1983) erected genus Omyomymar Schauff for Paranaphoidea silvanum (Ogloblin), and in his phylogenetic hypothesis (Schauff 1984), placed it with Erythmelus Enock and Anaphes Haliday. Later, Lin et al. (2007) placed Omyomymar in Anagrus-group of the genera of Mymaridae (Hymenoptera: Chalcidoidea) based on partially or completely divided posterior scutellum. LIN \& CHIAPPINI (1996) recorded the genus from China, described three species, and provided a key to the females of the then-existing species. MANICKAVASAGAM et al. (2011) reported the occurrence of the genus in India and recorded O. slivanum (Ogloblin). Anwar et al. (2015) described two species (Omyomymar insulanum Zeya \& Anwar and Omyomymar yusufi Anwar \& Zeya) from India with an updated list of world species and their distribution. GowripRAKASH \& MANICKAVASAgAm (2016) reported 0 . slivanum from India to be a misidentification and described it as O. huberi Manickavasagam \& Gowriprakash along with another very closely related species 0 . noyesi Manickavasagam \& Gowriprakash, both are collected from the same localities. RAMESHKUMAR et al. (2015) recorded 0. glabrum Lin \& Chiappini from Meghalaya. SAnKARARAman \& Manickavasagam (2020) described O. hayati Manickavasagam \& Sankararaman. Currently, the genus contains six species from India (excluding two species described here as new).

The objective of this paper is to describe, illustrate and diagnose two new species of genus based on two distinct females, collected from Himachal Pradesh and Sikkim states of Indian Himalayan regions. An identification key to all the known species of the genus from India is also provided. The validity of previously recorded and described Indian species is analyzed and discussed.

\section{MATERIAL AND METHODS}

The studied specimens are deposited at Insect Collections Department of Zoology, Aligarh Muslim University, Aligarh, Uttar Pradesh, India (ZDAMU). Collection and preservation techniques follow Noyes (1982). Dry specimens were mounted on cards of the sizes $(14 \times 5 \mathrm{~mm})$, cut by a card-punching machine (QAMAR 2016). Slides were prepared following HUBER (2015) and Anwar et al. (2020). The terminology used follows ZEYA \& HAYAT (1995), and GIBSON (1997). All measurements are in $\mu \mathrm{m}$. Body lengths are taken from card-mounted specimens; all other measurements are from slide mounts made at $400 \times$ magnification. The radicle remained attached to the head on slide, so, its length is not included with the scape. The illustrations of body parts mounted on slide were taken with a digital camera "Leica DFC295" attached to a compound microscope "Leica DM 2500", whereas the habitus view of insects on cards was taken under the stereo zoom binocular "Nikon SMZ25". The photographs were slightly cleaned and retouched using Adobe Photoshop ${ }^{\circledR}$ CS3.

The following abbreviations are used:

F, funicle segment; mps, multiporous plate sensillum or sensilla (= longitudinal sensilla of authors); MT, malaise trap; SN, sweep net; YPT, yellow pan trap; ICAR, Indian council of Agricultural Research.

\section{RESULTS AND DISCUSSION}

Key to Indian species of Omyomymar Schauff (females)

1. Clava without apical projection (Figure 2) ............................2

- Clava with apical projection (Figure 11, indicated by arrow) 
4

2. Clava at least $3.5 \times$ as long as broad, shorter than F4-F6 combined

O. glabrum Lin \& Chiappini

- Clava at most $3 \times$ as long as broad, as long as F4-F6 combined

...3

3. Clava $2.5 \times$ as long as broad; apical fourth of fore wing sparsely setose; marginal fringe of both wings relatively thick and fewer in number; ovipositor $3.5 \times$ as long as metatibia...

O. yousufi Anwar \& Zeya

- Clava 2.2x as long as broad; apical fourth of fore wing densely setose (Figure 4); marginal fringe of both wings relatively thin and more in number; ovipositor $2.3 \times$ as long as metatibia

O. supremus sp. nov. Anwar \& Zeya

4. Apical projection of clava finger-like, projected part at least $2 \times$ as long as broad (Figure 11); ovipositor at most $2.5 \times$ mesotibia length

O. sudhiri sp. nov. Anwar \& Zeya

- Apical projection of clava nipple-like, projected part at most $1 \times$ as long as broad; ovipositor at least $2.9 \times$ mesotibia length

....5

5. Clava longer than F3-F6 combined

O. insulanum Zeya \& Anwar

- Clava shorter than F3-F6 combined ...................................... 6

6. Clava at most $3.1 \times$ as long as wide, as long as F4-F6 combined; F1 distinctly longer than F2

O. hayati Manickavasagam \& Sankararaman

Clava at least $3.6 \times$ as long as wide, longer than F4-F6 combined; F1 at most or, slightly longer than F2 .................. 7

7. F1 the longest; ovipositor 2.9× mesotibia length; exserted part of ovipositor $0.6 \times$ gaster length

O. huberi Manickavasagam \& Gowriprakash

- F2 the longest; ovipositor 5.3× mesotibia length; exserted part of ovipositor $0.9 \times$ gaster length

.. O. noyesi Manickavasagam \& Gowriprakash

Description of new taxa (listed in same order as keyed)

Omyomymar supremus sp. nov. Anwar \& Zeya

(Figures 1-8)

Nomenclatural Act Registered in ZooBank:

urn:Isid:zoobank.org:act:CFB54COE-5CA4-4F61-A8E8-C4A23DD75DCO

Type material. Holotype, female (on slide under 4 coverslips, slide No. MYM.698), INDIA: SIKKIM: Tadong (ICAR Comp.) (YPT), 3.XI.2014, Coll. K. Veenakumari, (ZDAMU).

Diagnosis. Omyomymar supremus sp. nov. can be distinguished from other the species of the genus by its larger body length $970 \mu \mathrm{m}$, which is nearly $660 \mu \mathrm{m}$ in all the other described species. The new species is probably closely related to 0 . yousufi Anwar \& Zeya in having its antennal clava without projection but differs in following characters: clava relatively broader, $2.2 \times$ as long as broad (clava relatively less broad, $2.5 \times$ as long as broad in 0 . yousufi), fore wing apically one-fourth densely setose (fore wing apically one-fourth less densely setose in 0 . yousufi), ovipositor $3 \times$ as long as mesotibia and $3.5 \times$ as long as metatibia (ovipositor $2.85 \times$ as long as mesotibia and $2.28 \times$ as long as metatibia in 0 . yousufi).

Description. Female holotype. Length, $970 \mu \mathrm{m}$ (excluding the exserted part of ovipositor). Head and eyes dark brown. Antenna with radicle, scape, pedicel and F1 pale brown, F2-F6 and clava brown. Mesosoma dark brown. Wings subhyaline. Legs, including coxae, pale brown. Metasoma in basal half yellow, rest dark brown; ovipositor pale brown.

Head (Figure 3). Head, $1.2 \times$ as broad as high. Antenna
(Figure 2) with scape $2.4 \times$ as long as broad; pedicel $1.8 \times$ as long as broad; funicular segments markedly decreasing in length distad, F1-F5 longer than broad; F1, longest with proximal and distal ends slightly dilated, F6 shortest, $1.3 \times$ as broad as long; clava 2.2× as long as broad, longer than F4-F6 combined, slightly truncated at apex and without projection; basal segment of clava with one mps, apical segment with four mps.

Mesosoma (Figure 5). Mesosoma 0.6× metasoma length. Mesoscutum (Figure 6) with polygonal reticulate sculpture, notaular lines complete; scutellum and frenum longitudinally striae (Figure 7); propodeum (Figure 8) medially smooth, sides with faint longitudinal polygonal sculpture. Fore wing (Figure 4) 8.4× as long as broad, with two lines of setae, each running parallel to its wing margin, disc one-fourth apically densely setose and a few setae behind venation; longest marginal seta about $1.7 \times$ as long as maximum wing width. Hind wing (Figure 4) $23.8 \times$ as long as broad, longest marginal seta $4.5 \times$ as long as maximum wing width.

Metasoma (Figure 5). Ovipositor strongly exserted beyond the apex of gaster, $1.9 \times$ as long as gaster, $3 \times$ as long as mesotibia and $3.5 \times$ as long as metatibia, exserted part as long as gaster length.

Measurements $(\mu \mathrm{m})$. head width: height, 200:165; antennal segments including radicle L:W - radicle, 15:20; scape, 95:40; pedicel, 50:28; F1, 100:13; F2, 75:15; F3, 65:15; F4, 38:20; F5, 30:25; F6, 28:35; clava, 130:60; mesosoma, 338; fore wing L:W, 948:113; longest marginal seta, 188; hind wing L:W, 893:38; longest marginal seta, 170; protibia, 185; mesotibia, 378; metatibia, 325; gaster, 600; ovipositor, 1130; exserted part of ovipositor, 630.

Male. Unknown.

Host. Unknown.

Distribution. India: Sikkim.

Etymology. The species name is an arbitrary combination of letters and may be taken as a noun in apposition.

Omyomymar sudhiri sp. nov. Anwar \& Zeya (Figures 9-15)

\section{Nomenclatural Act Registered in ZooBank:} urn:Isid:zoobank.org:act:CEA15B7B4-DF44-43AD-B871-315B82588E35

Type material. Holotype, female (on slide under 4 coverslips, slide No. MYM.697): INDIA: HIMACHAL PRADESH: Gandawal, Una, (SN), 30.IX.2013, Coll. PT Anwar, (ZDAMU).

Diagnosis. Omyomymar sudhiri sp. nov. is close to O. silvanum Schauff and $O$. longidigitum Lin \& Chiappini, but differing from them for details of morphological characteristics, as discussed below.

O. sudhiri sp. nov. probably closely related to 0 . silvanum in having apical part of clava with projection, however, both differs from each other in following characters: antenna with funicle segments relatively shorter, F6 slightly broader than long; clava with finger-like projection, projected part $2 \times$ as long as broad (antenna with funicle segments relatively longer, F6 distinctly longer than broad; clava with the nipple-like process, projected part broader than long in 0 . silvanum); fore wing $9 \times$ as long as broad (fore wing $7.3 \times$ as long as broad in O. silvanum). O. sudhiri sp. nov. also comes close to $O$. longidigitum from China in having dorsal margin of F6 excised however it differs from the latter in having antenna with F2 the longest; F6 subquadrate; clava longer than F4-F6 combined; basal segment of clava $0.7 \times$ apical 

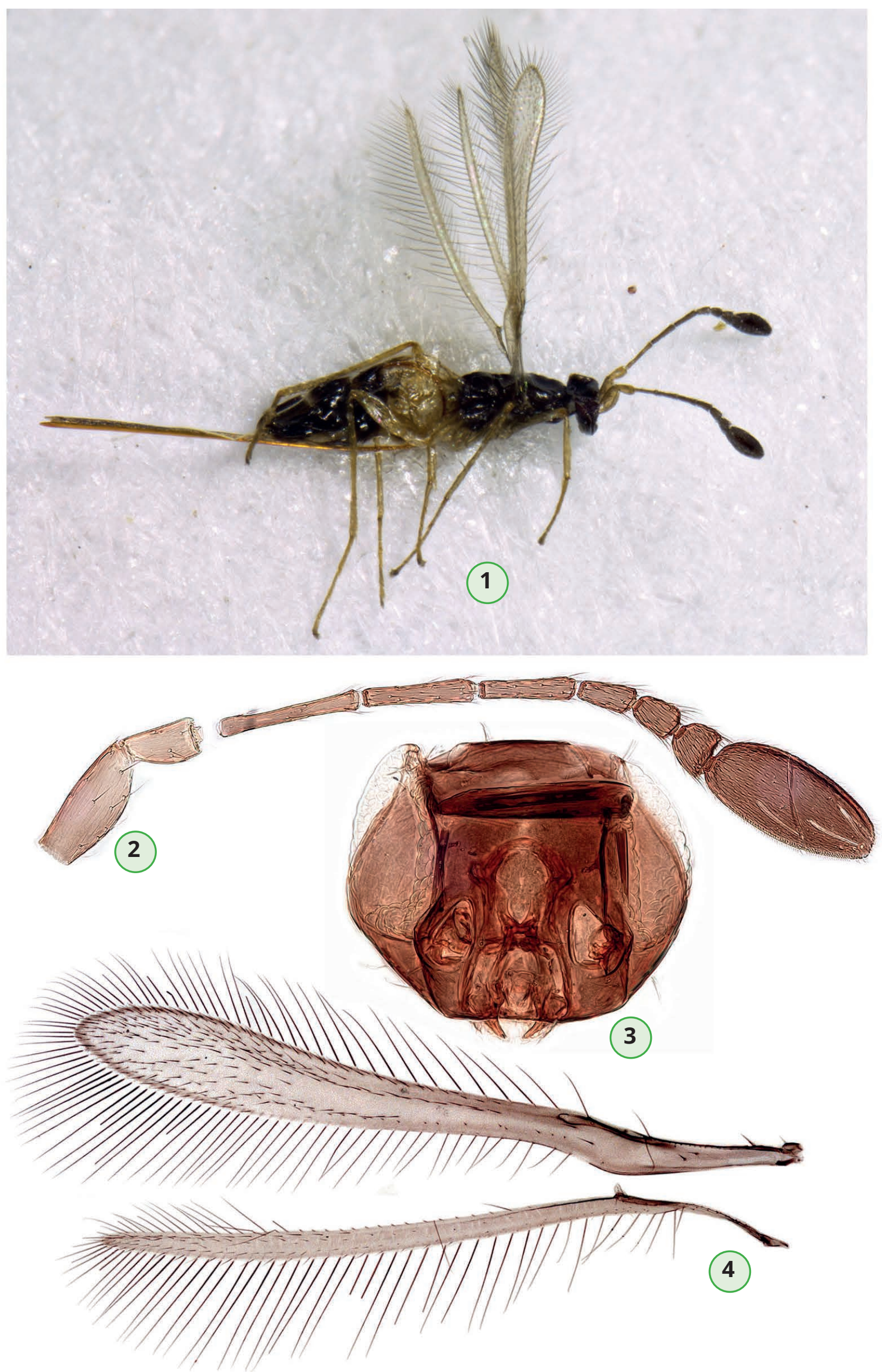

Figures 1-4. Omyomymar supremus sp. nov., female (Holotype). 1. Habitus. 2. Antenna. 3. Head, frontal view. 4. wings. 


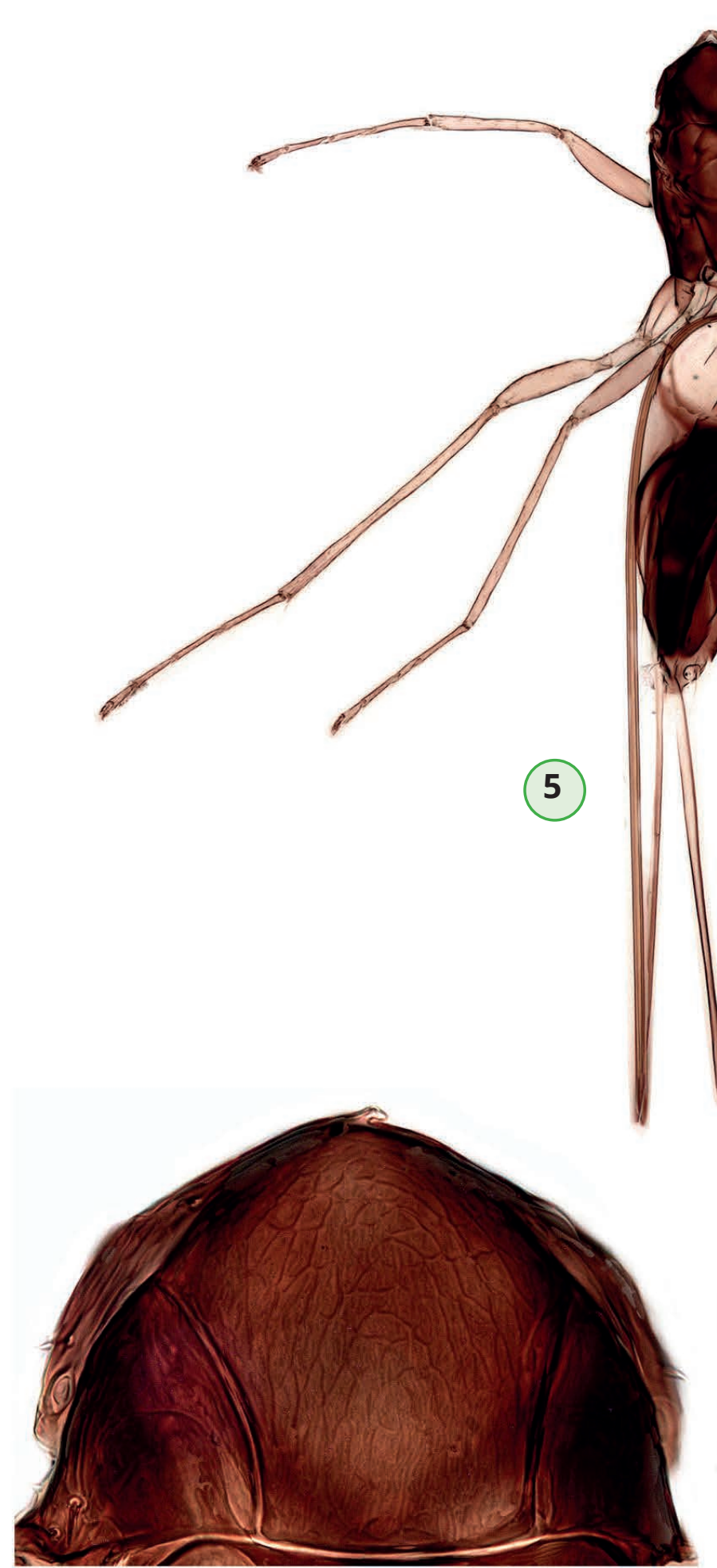

6

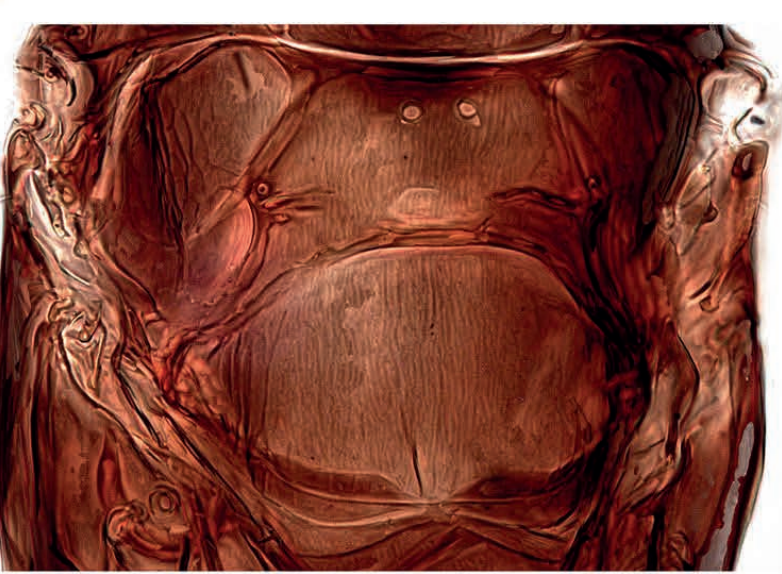

(7)

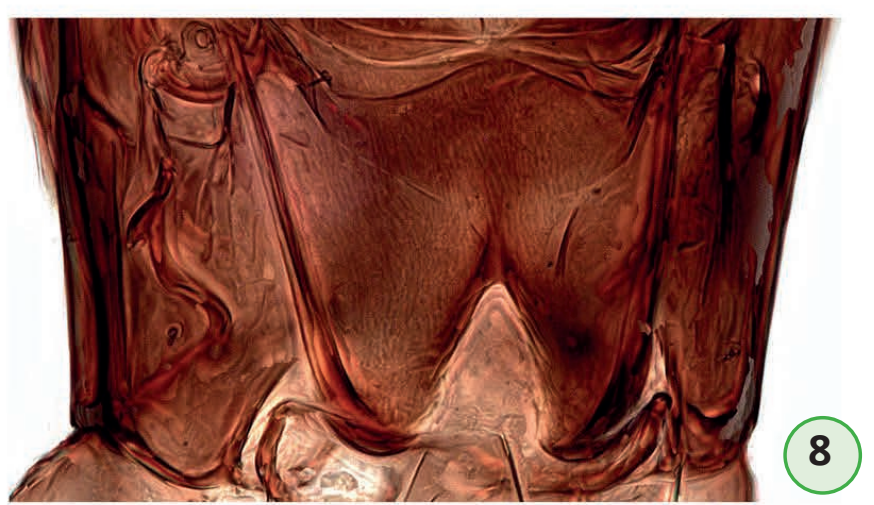

Figures 5-8. Omyomymar supremus sp. nov., female (Holotype). 5. Mesosoma and metasoma, dorsal view. 6. Mesoscutum, dorsal view. 7. Scutellum, dorsal view. 8. Propodeum, dorsal view. 


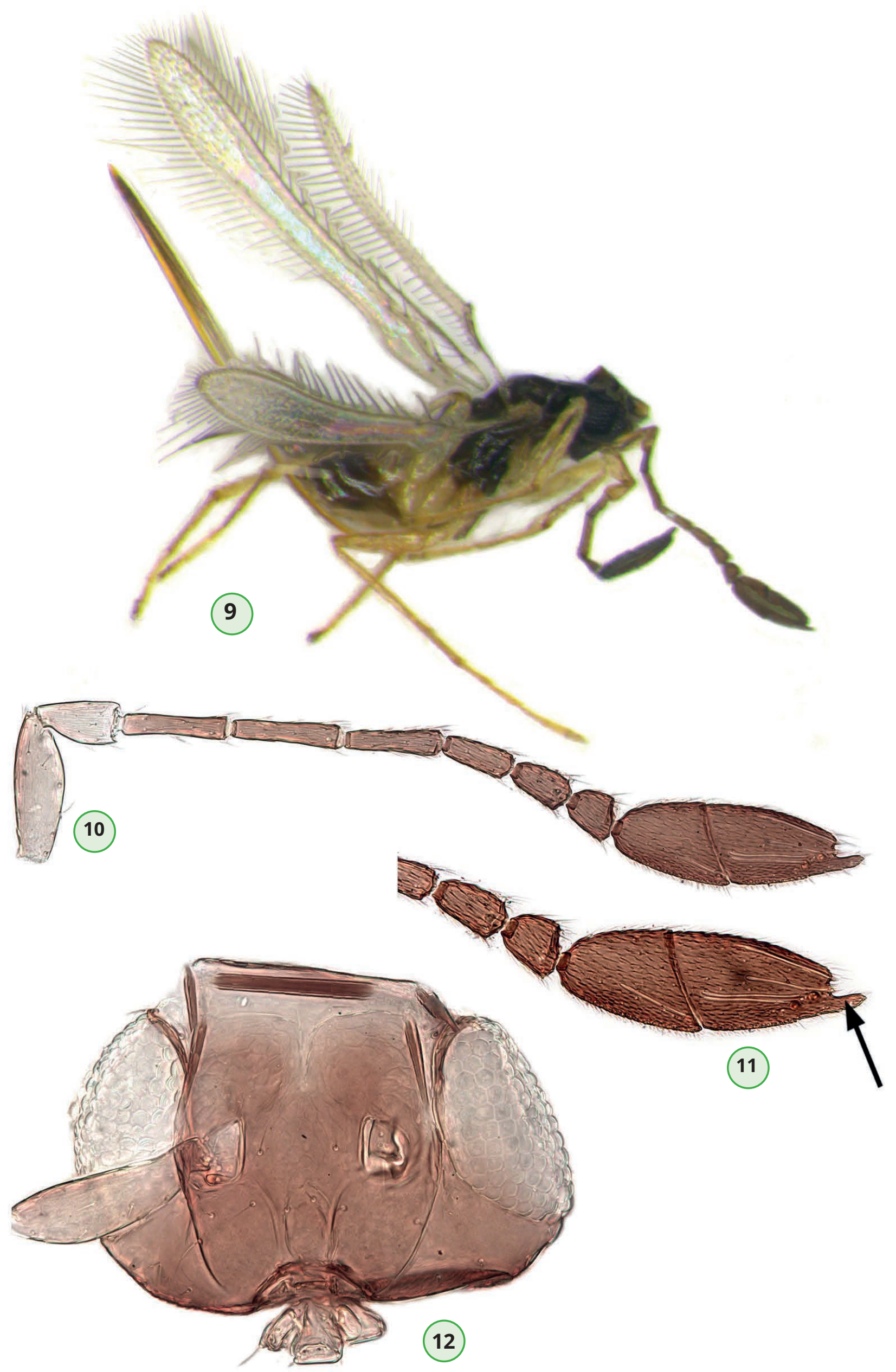

Figures 9-12. Omyomymar sudhiri sp. nov., female (Holotype). 9. Habitus. 10. Antenna. 11. F5, F6 and clava enlarged, arrow indicates apical projection on clava. 12. Head, frontal view. 

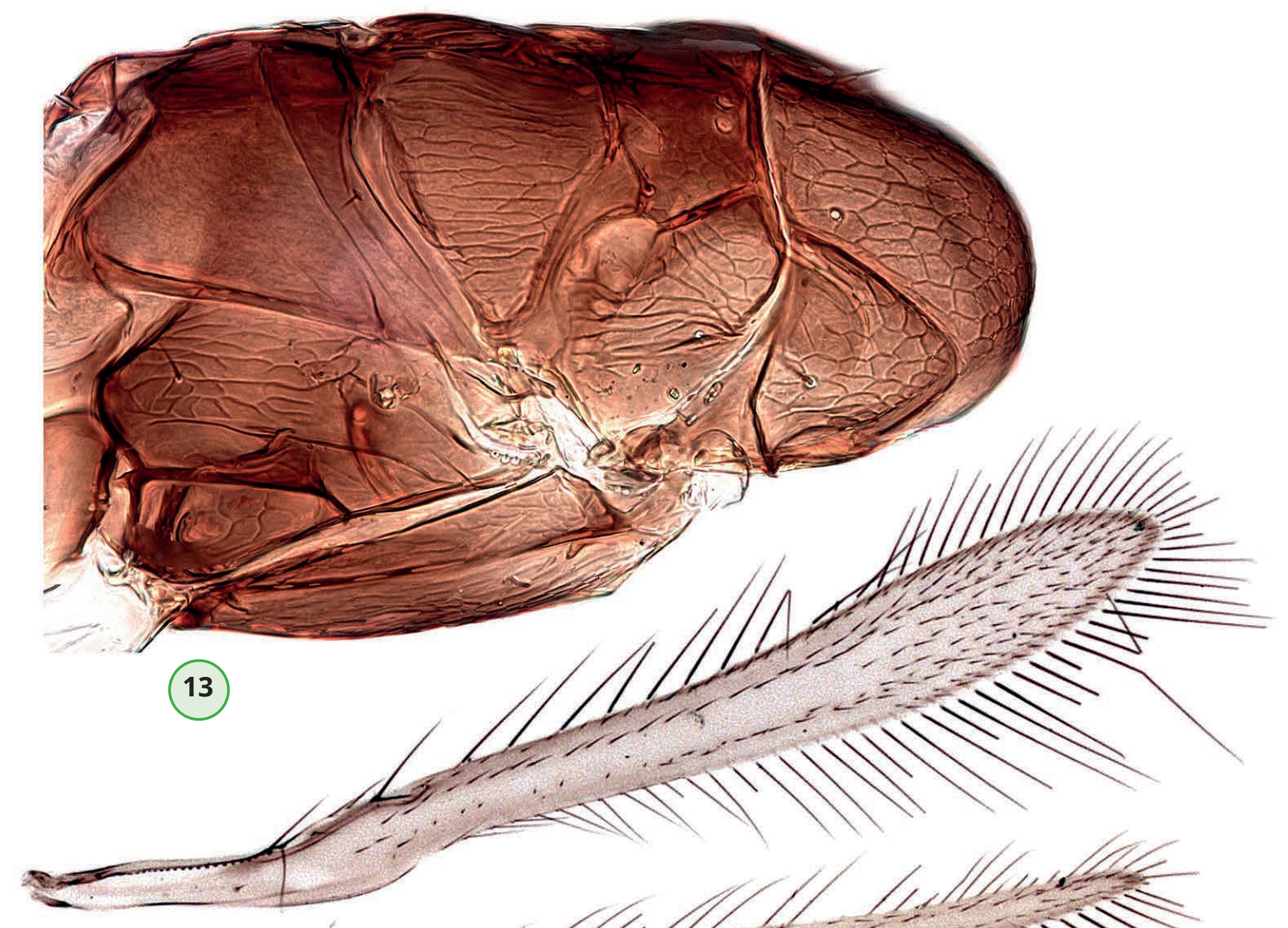

14

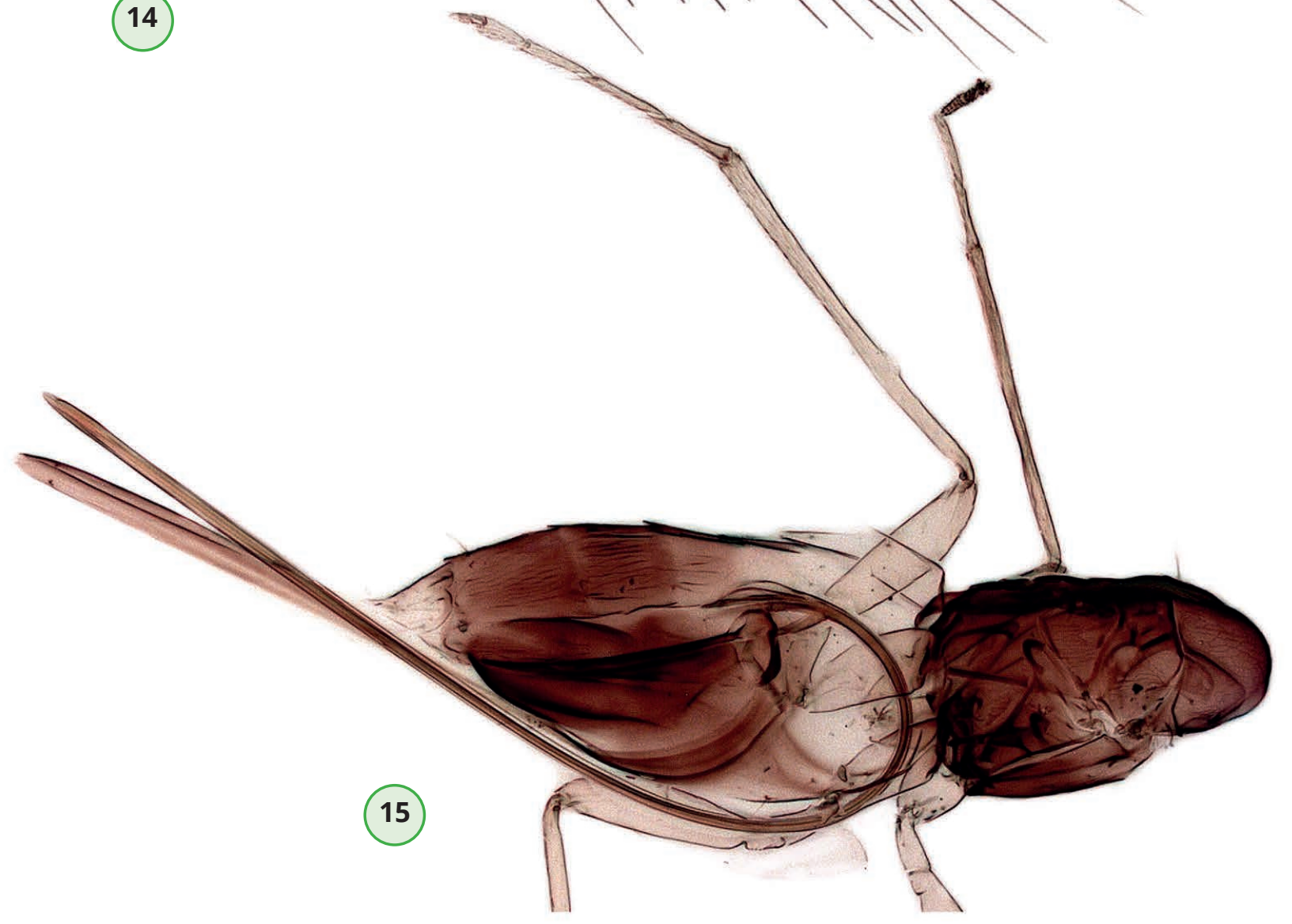

Figures 13-15. Omyomymar sudhiri sp. nov., female (Holotype). 13. Mesosoma, dorsolateral view. 14. Wings. 15. Mesosoma and metasoma, dorsolateral view. 
segment; ovipositor longer than body; exserted part of ovipositor $0.67 \times$ as long as gaster (in O. longidigitum F1 the longest; F6 distinctly longer than broad; clava shorter than F4-F6 combined; basal segment of clava about $0.5 \times$ length of the apical segment; ovipositor shorter than body length; exserted part of ovipositor $0.85 \times$ as long as metasoma).

Description. Female holotype. Length, $570 \mu \mathrm{m}$ (excluding exserted ovipositor). Body dark brown except metasoma in basal two-third pale brown. Antenna brown, clava with apical projection. Wings subhyaline. Legs, including coxae, pale yellow. Ovipositor pale brown.

Head (Figure 12). Head, $1.4 \times$ as broad as high. Antenna (Figure 10) with scape $2.8 \times$ as long as broad; pedicel $1.6 \times$ as long as broad; funicular segments decreasing in length distally; F1-F5 distinctly longer than broad, F6 subquadrate, widening apically; F2 the longest; clava with projection, $3 \times$ as long as broad, longer than F4-F6 combined; basal segment of clava with one placoid sensillum and, with one mps; apical segment with two placoid sensilla and, with four mps, projected part of clava $2 \times$ as long as broad (Figure 11).

Mesosoma (Figures 13, 15). Mesosoma 0.6× metasoma length. Mesoscutum with notaular lines complete, reticulated (Figure 13); mid lobe of mesoscutum with 2 setae, lateral lobe with one seta at lateral angle; scutellum with polygonal reticulation, $0.6 \times$ frenum, a pair of setae in the middle and one seta near each axilla; frenum with longitudinally stretched polygonal reticulation; propodeum $1.3 \times$ as long as scutellum, medially smooth, sides with polygonal sculpture (Figure 13). Fore wing (Figure 14) $9 \times$ as long as broad, with two lines of setae, each running parallel to its wing margin, disc one-fourth apically densely setose and a few setae behind venation; longest marginal seta $1.6 \times$ as long as maximum wing width. Hind wing (Figure 14) $26 \times$ as long as broad, longest marginal seta $4 \times$ as long as maximum wing width.

Metasoma (Figure 15). Ovipositor strongly exserted beyond apex of gaster, $1.8 \times$ as long as gaster, $3 \times$ as long as mesotibia and $2.5 \times$ as long as metatibia; exserted part of ovipositor $0.7 \times$ gaster length.

Measurements $(\mu \mathrm{m})$. head width:height, 215:155; antennal segments including radicle L:W - radicle, 15:13; scape, 78:28; pedicel, 40:25; F1, 55:10; F2, 58:13; F3, 50:13; F4, 35:15; F5, 28:18; F6, 23:25; clava, 138:45; claval process, 15; mesosoma, 250; fore wing L:W, 725:80; longest marginal seta, 125; hind wing L:W, 713:28; longest marginal seta, 113; protibia, 143; mesotibia, 238; metatibia, 293; gaster, 415; ovipositor, 725; exserted part of ovipositor, 278.

Male. Unknown.

Host. Unknown

Distribution. India: Himachal Pradesh.

Etymology. The species is named in honor of Dr. Sudhir Singh, Head of Entomology Section, Forest Research Institute, Dehradun, India, for his contributions to the taxonomy of the Indian Chalcidoidea.

\section{DISCUSSION}

Species of Omyomymar is among a few genera of Mymaridae that represent a long exserted ovipositor except $O$. andriescui Pricop (PRICOP 2014). Consequently, ovipositor length to tibial ratio is an important character in differentiating two or more closely related species. As for the available data records, for Mymaridae with the longest ovipositor, the ovipositor length to metatibia ratio is $6.28 \times$ [for Tanyxiphium harriet (Zeya), (ZeYA 2015)]; however, the ratio may surpass for some species of Australomymar Girault (see, figure 50 in Noyes \& VALENTINE 1989) and species of Borneomymar Huber (MICHAEL et al. 2013).

MANICKAVASAGAM et al. (2011) recorded O. slivanum from India which was later reported to be misidentified and described as O. huberi Manickavasagam \& Gowriprakash (GoWRIPRAKASH \& Manickavasagam 2016). Gowriprakash \& Manickavasagam (2016) described another species O. noyesi Manickavasagam \& Gowriprakash collected from the same localities, which seems to be similar except for some measurements, that could be an artifact of poor slide preparation and erroneous morphometric and data records (see page 394 in Manickavasagam et al. 2011 and pages 3,4 in GowrIPRAKASH \& Manickavasagam 2016) and hence may be conspecific. The recorded ovipositor-mesotibial ratio is $2.9 \times$ for 0 . huberi and $5.3 \times$ for 0 . noyesi. We strongly believe that the authors wrongly recorded the measurements for the latter species which cannot be more than $3 \times$ (see figure 6 (habitus) in GoWripRAKASH \& MANICKAVASAgAM 2016). The other recorded species O. glabrum Lin \& Chiappini by RAMESHKUMAR et al. (2015) seems to be conspecific with the Palaearctic species as it shares all its characters. Hence, it is clear that the genus in the Oriental Region needs a taxonomic revision to standardize descriptions and, reanalyze measurements.

\section{ACKNOWLEDGEMENTS}

We express our sincere gratitude to Dr. Mohammad Hayat, (ZDAMU) for his suggestions and criticism. We are thankful to the Chairman, Department of Zoology, AMU, Aligarh for providing research facilities. We are grateful to Dr. K. Veenakumari, National Bureau of Agricultural Insect Resources, Bengaluru (NBAIR), for donating the specimens collected by them for study. We thank Dr. D.A. Aquino, Museo de La Plata, Universidad Nacional de la Plata, La Plata, Buenos Aires, Argentina (MLPA), for his comments and comparison of Omyomymar sudhiri with $O$. silvanum. The help rendered by Prof. (Retd.) Lin Nai-quan, Fujian Agriculture and Forestry University, Fuzhou, China (FAFU), and Prof. ChaoDong Zhu, Institute of Zoology, Chinese Academy of Sciences, Beijing China is highly appreciated. The first author gratefully acknowledges the Council of Scientific \& Industrial Research (CSIR), New Delhi, for providing financial support in the form of "Research Associateship".

\section{REFERENCES}

Anwar, PT, SB Zeya \& K Veenakumari, 2020. Fairyfly genus Camptoptera Foerster (Hymenoptera: Chalcidoidea: Mymaridae) in India and Sri Lanka, with descriptions of eleven new species. Zoologica, 165: 1-89.

Anwar, PT, SB Zeya \& K Veenakumari, 2015. Two new species of Omyomymar Schauff (Hymenoptera: Mymaridae) from India. Journal of Insect Systematics, 1: 139-144.

Gibson, GAP, 1997. Chapter 2. Morphology and terminology, pp. 16-44. In: Gibson, GAP, JT Huber \& JB Woolley (Eds.). Annotated keys to the genera of Nearctic Chalcidoidea (Hymenoptera). National Research Council of Canada, NRC Research Press, Ottawa, Ontario, Canada.

Gowriprakash, J \& S Manickavasagam, 2016. Two new species of Omyomymar schauff (Hymenoptera: Mymaridae) from India with key to oriental species. Journal of Insect Biodiversity, 4: 1-8. DOI: https://doi.org/10.12976/ $\mathrm{jib} / 2016.4 .20$

Huber, JT, 2015. World reclassification of the Gonatocerus group of genera (Hymenoptera: Mymaridae). Zootaxa, 3967: 1-184. DOI: https://doi.org/10.11646/ zootaxa.3967.1.1

Lin, NQ \& E. Chiappini, 1996. First record of Omyomymar (Hymenoptera: Mymaridae) from China, with the descriptions of three new species. Proceedings of the 
Entomological Society of Washington, 98: 301-307.

Lin, NQ, JT Huber \& J LaSalle, 2007. The Australian genera of Mymaridae (Hymenoptera: Chalcidoidea). Zootaxa, 1596: 1-111.

Manickavasagam, S, A Rameshkumar \& K Rajmohana, 2011. First report of four species of fairyflies from India, Key to Indian species of four genera and additional distributional records of Mymaridae (Hymenoptera: Chalcidoidea). Madras Agricultural Journal, 98: 393-408. DOI: https://doi.org/10.11646/zootaxa.3094.1.5

Michael, SE, RC McKellar \& JT Huber, 2013. A fossil species of the primitive mymarid genus Borneomymar (Hymenoptera: Mymaridae) in Eocene Baltic amber. Novitates Paleoentomologicae, 5: 1-8. DOI: https://doi.org/10.17161/np.v0i5.4651

Noyes, JS, 1982. Collecting and preserving chalcid wasps (Hymenoptera: Chalcidoidea). Journal of Natural History, 16: 315-334. DOI: https://doi.org/10.1080/00222938200770261

Noyes, JS \& EW Valentine, 1989. Mymaridae (Insecta: Hymenoptera) - introduction and review of genera. Fauna of New Zealand, 17: 1-95.

Pricop, E, 2014. First record of Omyomymar (Hymenoptera: Chalcidoidea: Mymaridae) from Europe, with description of a new species from Romania. North-West Journal of Zoology, 10: 562-566.

Qamar, A, 2016. Designing and fabrication of an improvised card-punching machine for dry mounting of small insects.
Journal of Insect Systematics, 3: 147-150.

Rameshkumar, A, J Poorani \& V Naveen, 2015. Additions to the Encyrtidae and Mymaridae (Chalcidoidea) of India with new distribution and host records for some species. Biodiversity Data Journal, 3: e5216. DOI: https://doi.org/10.3897/bdj.3.e5216

Sankararaman, H \& S Manickavasagam, 2020. Description of a new species of Omyomymar Schauff from India with a key to Oriental species and first report of Palaeoneura markhoddlei Triapitsyn (Hymenoptera: Mymaridae) from the Indian subcontinent. Journal of Threatened Taxa, 12: 17003-17008. DOI: https://doi.org/10.11609/ jott.6124.12.14.17003-17008

Schauff, ME, 1983. A new genus of Mymaridae (Hymenoptera: Chalcidoidea). Proceedings of the Entomological Society of Washington, 85: 543-551.

Schauff, ME, 1984. The Holarctic genera of Mymaridae (Hymenoptera: Chalcidoidea). Memoirs of the Entomological Society of Washington, 12: 1-67.

Zeya, SB, 2015. Description of a new species of Gonatocerus Nees (Hymenoptera: Mymaridae) from India, with some records. Journal of Insect Systematics, 1: 85-91.

Zeya, SB \& M Hayat, 1995. A revision of the Indian species of Gonatocerus Nees (Hymenoptera: Chalcidoidea: Mymaridae). Oriental Insects, 29: 47-160.
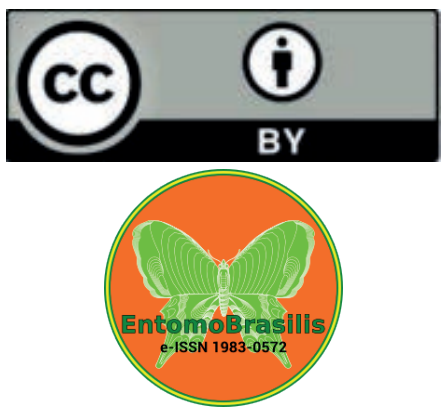

$* * * * * * * * * *$

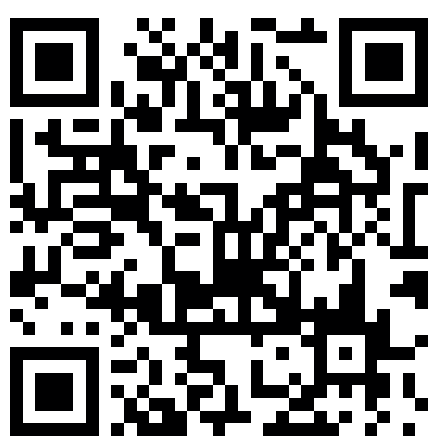

